\section{CIVILTEC}

Revista Técnico-Cientifica

de Engenharia Civil
Volume $2-$ n. $2-2021$

htrp://periodicos.unesc.net/engcivil

\title{
Duração do período seco como critério para dimensionamento de reservatório de água da chuva
}

Doi: http://dx.doi.org/10.18616/civiltec.v2i2.6845

Álvaro José Back ${ }^{1}$

\section{Introdução}

O dimensionamento do volume do reservatório ou cisterna é um dos pontos mais importantes para a definição da viabilidade técnica e econômica do projeto de captação da água da chuva. Existem diversos métodos descritos na literatura, que podem levar a resultados diferenciados (TOMAZ, 2015). Um critério para dimensionamento de reservatórios baseado nas caraterísticas da chuva é o que considera a duração máxima do período seco. Este método consiste em determinar o período máximo de dias secos consecutivos que ocorre com um dado período de retorno. A norma técnica NBR 15527 (ABNT, 2019) recomenda que o estudo de viabilidade técnica e econômica do sistema de capação de água da chuva deva considerar os estudos das séries históricas de precipitação da região onde será feito o projeto. Este estudo teve como objetivo analisar a série histórica de chuva, de uma estação pluviométrica de SC, para estabelecer a duração do período seco a ser usado no dimensionamento do reservatório de água da chuva.

\section{Material e Métodos}

Foram usados os dados de precipitação da estação pluviométrica de Meleiro (Código 02849005 , Latitude $-28,8322^{\circ}$, Longitude $-49.6367^{\circ}$, Altitude $80 \mathrm{~m}$ ) pertencente à rede de estações hidrológicas da Agência Nacional de Águas e Saneamento Básico (ANA, 2021). Foram usados os dados diários do período de 1943 a 2020. Algumas falhas nos dados foram preenchidas com dados de estações pluviométricas mais próximas. Foram determinadas as séries mensais e anuais de duração máxima do período seco consecutivo, considerando como dias secos os dias com chuva inferior a $2 \mathrm{~mm}$ e $5 \mathrm{~mm}$. O período seco foi computado no mês relativo ao fim da sua duração. Com a série de máximas anuais, foram estimados os valores esperados para os períodos de retorno de 2 a 100 anos, usando a distribuição de Gumbel-Chow (BACK, 2013).

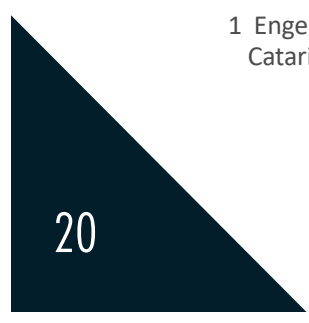

1 Engenheiro Agrônomo, Dr. em Engenharia, pesquisador da Empresa de Pesquisa Agropecuária e Extensão Rural de Santa Catarina, Estação Experimental de Urussanga; professor do curso de Engenharia Civil da Unesc, alvarojoseback@gmail.com 


\section{CIVILTEC}

Revista Técnico-Científica

de Engenharia Civil
Volume $2-$ n. $2-2021$

http://periodicos.unesc.net/engcivil

\section{Resultados e discussão}

Para o critério de dias secos com chuvas inferior a $2 \mathrm{~mm}$, a duração máxima mensal variou de 2 a 68 dias, com médias mensais entre 7,4 e 15,1 dias. Nos meses do inverno, ocorre maior duração de período seco, com valores médios acima de 12 dias nos meses de maio a setembro (figura 1A). Para o critério com chuvas inferior a $5 \mathrm{~mm}$ a média mensal variou de 9,2 a 19,2 dias, sendo nos meses de maio a setembro a média do período seco superior a 15 dias (figura $1 \mathrm{~B})$.
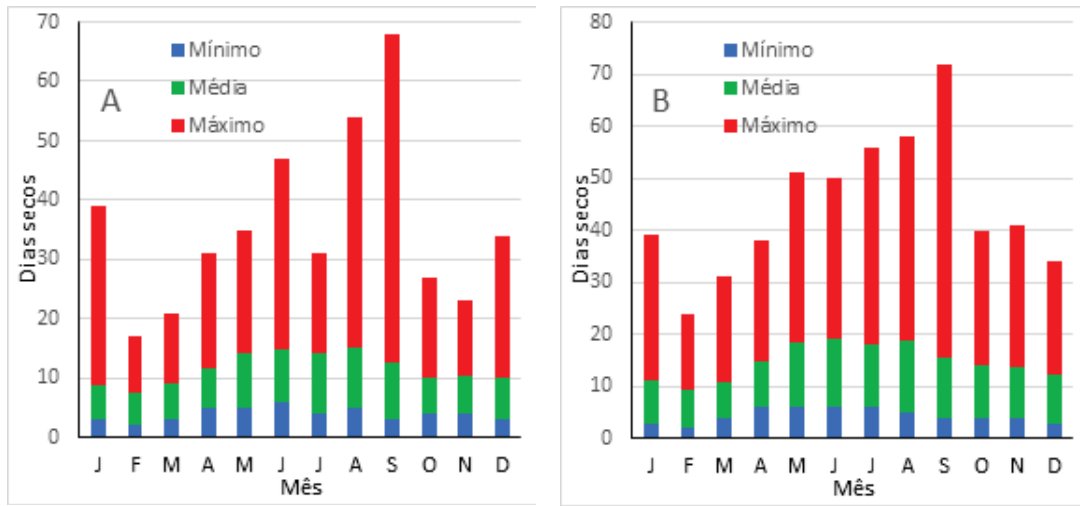

Figura 1. Estatísticas das séries mensais de duração do período seco no período de 1943 a 2000, considerando os critérios de chuva $<2 \mathrm{~mm}(\mathrm{~A})$ e chuva $<5 \mathrm{~mm}$ (B), para Meleiro, SC.

(Fonte: elaboração própria)

As séries de máximas anuais de dias secos estão representadas na figura 2, onde observa-se que para $\mathrm{P}<2 \mathrm{~mm}$ a média foi de 23,2 dias, com valores variando de 11 dias (ano de 1983) a 68 dias (ano de 1951). Para critério de $P<5 \mathrm{~mm}$, os valores da seca máxima anual variaram de 15 dias (ano de 1998) a 72 dias (ano de 1951), com média de 29 dias. Na tabela 1 , constam os valores de duração máxima do período seco estimado para diferentes períodos de retorno. No sistema de captação da água da chuva, é recomendado que o volume inicial equivalente a $2 \mathrm{~mm}$ de chuva seja descartado (NBR 15527 ABNT, 2019). Dessa forma, pode-se considerar período seco os dias consecutivos com chuva inferior a $2 \mathrm{~mm}$. Dornelles et al. (2010) citam que o modelo teórico mais indicado é o que utiliza a distribuição de probabilidade de extremos, a exemplo de Gumbel. Os autores recomendam considerar o período de retorno variando de 3 a 10 anos. Adotando o período de retorno de 5 anos, pode-se recomendar o dimensionamento do reservatório de captação de água da chuva para atender à demanda de um período de 30 dias, em que chuvas inferiores a $2 \mathrm{~mm}$ são descartadas. Para locais com maior acúmulo de sujeira no telhado, adotando o descarte dos primeiros $5 \mathrm{~mm}$ da chuva (TOMAZ, 2011), o reservatório deve ser dimensionado para período de 38 dias. Esses valores são superiores ao período de 15 dias indicado no método da Embrapa (2005) para armazenamento de água da chuva para a atividade pecuária. 


\section{CIVILTEC}

Revista Técnico-Cientifica

de Engenharia Civil
Volume $2-$ n. $2-2021$

http://periodicos.unesc.net/engcivil

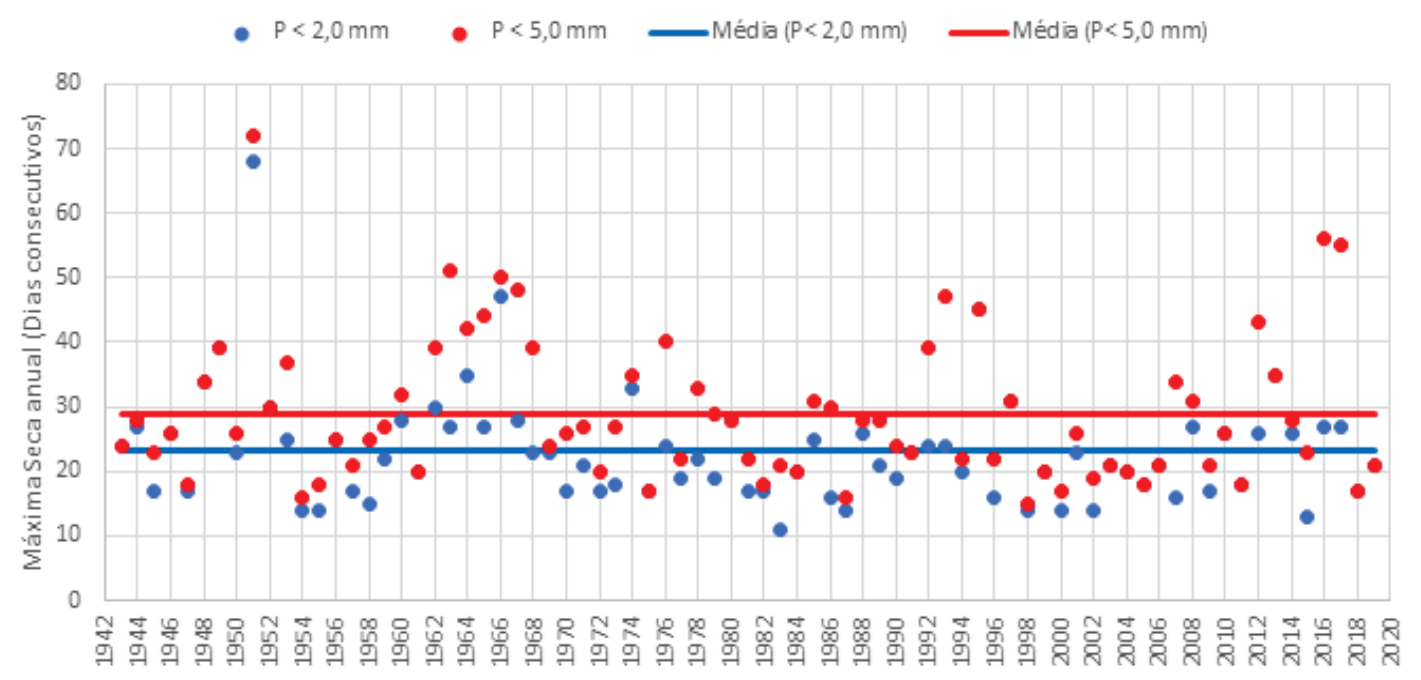

Figura 2. Série histórica de duração máxima do período seco de Meleiro-SC. (Fonte: elaboração própria)

Tabela 1. Duração da máxima seca anual (dias) (Fonte: elaboração própria)

\begin{tabular}{lll}
\hline $\begin{array}{l}\text { Período de retorno } \\
\text { (Anos) }\end{array}$ & \multicolumn{2}{l}{ Critério de dias secos } \\
\cline { 2 - 3 } & Chuva inferior a 2,0 $\mathbf{~ m m}$ & Chuva inferior a 5,0 $\mathbf{~ m m}$ \\
\hline 2 & 21,8 & 27,2 \\
3 & 25,8 & 32,2 \\
5 & 30,1 & 37,8 \\
10 & 35,6 & 44,8 \\
15 & 38,7 & 48,7 \\
20 & 40,8 & 51,5 \\
25 & 42,5 & 53,6 \\
50 & 47,6 & 60,2 \\
100 & 52,7 & 66,7 \\
\hline
\end{tabular}

\section{Conclusões}

A duração do período máximo anual com chuvas menores que $2 \mathrm{~mm}$ de Meleiro tem média de 23,2 dias e, para o limite de $5 \mathrm{~mm}$, a duração média é de 29 dias. No sistema de captação de água da chuva em que são descartadas as chuvas inferiores a $2 \mathrm{~mm}$, adotando o período de retorno de 5 anos, o reservatório deve ser dimensionado para atender à demanda do período de 30 dias sem chuva. No estudo, foram apresentados valores para

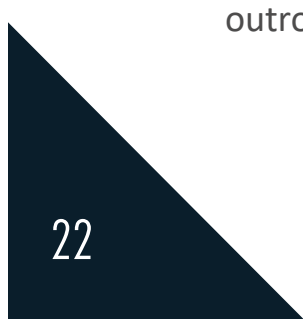
utros períodos de retorno que podem ser usados conforme o risco admitido no projeto. 


\section{CIVILTEC}

Revista Técnico-Científica de Engenharia Civil
Volume $2-$ n. $2-2021$

http://periodicos.unesc.net/engcivil

Palavras-chave: Dias Secos. Cisterna. Estiagem. Captação de Água.

\section{Referências}

AGÊNCIA NACIONAL DE ÁGUAS E SANEAMENTO BÁSICO - ANA. Hidroweb: Sistemas de Informações Hidrológicas. Disponível em: <http:// hidroweb.ana.gov.br>. Acesso em: 11 set. 2021.

ASSOCIAÇÃO BRASILEIRA DE NORMAS TÉCNICAS. NBR 15527: água de chuva - aproveitamento de coberturas em áreas urbanas para fins não potáveis - requisitos. Rio de Janeiro, 2019.

BACK, Á. J. Chuvas intensas e chuva para dimensionamento de estruturas de drenagem para o Estado de Santa Catarina. Florianópolis: Epagri, 2013. p. 193.

DORNELLES, F.; TASSI, R. GOLDENFUM, J. A. Avaliação das técnicas de dimensionamento de reservatórios para aproveitamento de água de chuva. Revista Brasileira de Recursos Hídricos, v. 15, n. 2, 2010. p. 59-68

EMBRAPA. Manejo da água na produção de suínos. Concórdia, Embrapa-CNPSA, 2005. 19 p.

TOMAZ, P. Aproveitamento de água de chuva para áreas urbanas e fins não potáveis. São Paulo: Navegar Editora, 2011. 208p. 